\title{
BMJ Open Study protocol for a multicentre, $2 \times 2$ factorial, randomised, controlled trial evaluating the interest of intravenous iron and tranexamic acid to reduce blood transfusion in hip fracture patients (the HiFIT study)
}

Sigismond Lasocki (1) , ${ }^{1}$ Thibault Loupec, ${ }^{2}$ Elsa Parot-Schinkel, ${ }^{3}$ Bruno Vielle, ${ }^{3}$ Marc Danguy des Déserts, ${ }^{4}$ Antoine Roquilly, ${ }^{5}$ Maria Lahlou-Casulli, ${ }^{6}$ Vincent Collange,${ }^{7}$ Olivier Desebbe, ${ }^{8}$ Alexis Duchalais, ${ }^{9}$ Bertrand Drugeon, ${ }^{10,11}$ Pierre Bouzat (D),$^{12}$ Delphine Garrigue, ${ }^{13}$ Benjamin Mounet, ${ }^{2}$ Franck Hamard, ${ }^{14}$ Jean-Stéphane David, ${ }^{15}$ Maxime Leger, ${ }^{1}$ Emmanuel Rineau, ${ }^{1}$ on behalf of the HiFIT Study Group

To cite: Lasocki S, Loupec T, Parot-Schinkel E, et al. Study protocol for a multicentre, $2 \times 2$ factorial, randomised, controlled trial evaluating the interest of intravenous iron and tranexamic acid to reduce blood transfusion in hip fracture patients (the HiFIT study). BMJ Open 2021;11:e040273. doi:10.1136/ bmjopen-2020-040273

- Prepublication history and additional material for this paper are available online. To view these files, please visit the journal online (http://dx.doi. org/10.1136/bmjopen-2020040273).

Received 21 June 2020 Revised 20 December 2020 Accepted 21 December 2020

Check for updates

(c) Author(s) (or their employer(s)) 2021. Re-use permitted under CC BY-NC. No commercial re-use. See rights and permissions. Published by BMJ.

For numbered affiliations see end of article.

Correspondence to Professor Sigismond Lasocki; sigismond@lasocki.com

\section{ABSTRACT}

Introduction Blood transfusion and anaemia are frequent and are associated with poor outcomes in patients with hip fracture (HF). We hypothesised that preoperative intravenous iron and tranexamic acid (TXA) may reduce the transfusion rate in these patients.

Methods and analysis The HiFIT study is a multicentre, $2 \times 2$ factorial, randomised, double-blinded, controlled trial evaluating the effect of iron isomaltoside (IIM) $(20 \mathrm{mg} /$ $\mathrm{kg}$ ) vs placebo and of TXA (intravenously at inclusion and topically during surgery) versus placebo on transfusion rate during hospitalisation, in patients undergoing emergency surgery for HF and having a preoperative haemoglobin between 95 and $130 \mathrm{~g} / \mathrm{L}$. 780 patients are expected. The primary endpoint is the proportion of patients receiving an allogenic blood transfusion of packed red blood cells from the day of surgery until hospital discharge (or until D30 if patient is still hospitalised). Enrolment started on March 2017 in 11 French hospitals. The study was stopped between July 2017 and August 2018 (because of investigation of serious AEs with IIM in Spain) and slowed down since March 2020 (COVID-19 crisis). The expected date of final follow-up is May 2022. Analyses of the intent-to-treat and per-protocol populations are planned.

Ethics and dissemination The HiFIT trial protocol has been approved by the Ethics Committee of Comité de Protection des Personnes Ouest II and the French authorities (ANSM). It will be carried out according to the principles of the Declaration of Helsinki and the Good Clinical Practice guidelines. The results will be disseminated through presentation at scientific conferences and publication in peer-reviewed journals. The HiFIT trial will be the largest study evaluating iron and TXA in patients with HF.

\section{Strengths and limitations of this study}

The HiFIT study will be the largest randomised controlled trial to evaluate both intravenous iron and tranexamic acid (TXA) in patients with hip fracture (two to four times the number of patients of previous studies); it should have sufficient power to detect serious adverse events (AEs).

- The administration of TXA will be performed through both intravenous and topic routes, which may improve efficacy and tolerance.

- HiFIT study will evaluate the benefit of iron and of TXA on rehabilitation at 3 months.

- All serious AEs are reported using standardised forms and adjudicated by an independent expert committee.

- Recruitment in the study has been hampered by external events (the study was suspended for 1 year because of serious AEs declared in Spain with iron isomaltoside and slowed down since March 2020 because of the COVID-19 crisis).

Trial registration number clinicalTrials.gov identifier: NCT02972294; EudraCT Number 2016-003087-40.

\section{INTRODUCTION}

Hip fractures (HFs) are very common, with an incidence of approximately 1.6 million cases per year worldwide. ${ }^{1}$ This high incidence is anticipated to grow rapidly in the next decades, driven by population ageing. By the year 2040, the estimated annual healthcare costs will reach $\$ 9.8$ billion in the USA. ${ }^{2}$ Currently, HFs are responsible for 
79000 hospitalisations per year in France, with an average length of hospital stay of 12.7 days. It is estimated that more than $16 \%$ of the French population will be over 85 years old in 2020 and $24 \%$ in 2050 . Moreover, age is a major risk factor for perioperative mortality, particularly after $\mathrm{HF}^{3}{ }^{3}$ Hospital mortality rate after $\mathrm{HF}$ is $3.6 \%$ in a recent French cohort of more than 319000 patients, ${ }^{4}$ and the mortality rate within 1 year is as high as $36 \%$ despite aggressive management including early surgery and rehabilitation. Among modifying factors associated with poorer outcome following HF, anaemia is the most prevalent. ${ }^{5}$ Indeed, anaemia is very frequent on admission for HF, affecting up to $45 \%$ of patients, with a mean haemoglobin $(\mathrm{Hb})$ level of $125 \pm 2 \mathrm{~g} / \mathrm{L}$. ${ }^{6}$ This high prevalence of preoperative anaemia together with blood losses, secondary to the fracture itself and to the surgery, are responsible for a high blood transfusion rate (approximately $40 \%-50 \%$ of patients).${ }^{56}$ Both anaemia and blood transfusion are associated with poor outcomes, including increased mortality. In a recent systematic review, preoperative anaemia was associated with a risk ratio (RR) for mortality of $1.64,95 \%$ CI (1.47 to 1.82$), \mathrm{p}<0.00001$ and blood transfusion with a RR of 1.53 (1.35 to 1.75), $\mathrm{p}<0.00001 .^{5}$ In addition, blood is a scarce and expensive resource and its use should be limited as much as possible. ${ }^{7}$ There is therefore a need to treat this anaemia and/or to prevent the decrease in postoperative haemoglobin. For this purpose, intravenous iron may be proposed as in patient blood management programmes, ${ }^{8-10}$ even using short-term perioperative treatment. ${ }^{11}$ Some nonrandomised, mainly retrospective, studies have shown that perioperative intravenous iron was able to reduce blood transfusion (ie, the number of patients transfused and the number of units per patient) in patients with HF (from $48.8 \%$ to $32.4 \%, p=0.001$, in a pooled analysis of 5 studies including 1361 patients). ${ }^{12}$ A small $(n=200$ patients), single-centre, randomised trial comparing intravenous iron ( $600 \mathrm{mg}$ of iron sucrose) to standard of care showed no difference in transfusion rate. ${ }^{13}$ Another randomised controlled trial (RCT), evaluating the same dose $(600 \mathrm{mg})$, given preoperatively and postoperatively, showed a significant increase in reticulocyte count (the primary endpoint) without significant reduction in transfusion rate. ${ }^{14}$ At last, in a study of 306 patients with HF, $1 \mathrm{~g}$ of ferric carboxymaltose with or without erythropoietin did not reduce the need for transfusion, but improved recovery from postoperative anaemia. ${ }^{15}$ There is thus no definitive data showing a benefit of giving intravenous iron preoperatively in patients with HF. New iron formulations allowing to deliver high doses of iron in one short intravenous injection (as much as $20 \mathrm{mg} / \mathrm{kg}$, maximum $2000 \mathrm{mg}$, over $30 \mathrm{~min}$ for iron isomaltoside (IIM)) are efficient to reduce postoperative anaemia when given on the day of surgery, ${ }^{16}$ when smaller iron doses (ie, $600 \mathrm{mg}$ ) were ineffective in patients with $\mathrm{HF} .{ }^{17}$ In addition, iron deficiency is responsible for fatigue and muscular weakness, which may be corrected by intravenous iron. ${ }^{18-22}$ This could be particularly important for this older population, for whom postoperative rehabilitation is of crucial importance.

Another way to reduce blood transfusion would be to reduce perioperative bleeding. Tranexamic acid (TXA) is efficient for this purpose both in trauma ${ }^{23}$ and in elective surgery patients. ${ }^{24}{ }^{25}$ However, when we designed this study, there were only two randomised trials investigating the interest of TXA in HFs, and they were not conclusive probably because of a lack of power. ${ }^{26}$ To date, eight new RCTs evaluate the interest of intravenous TXA, the largest one included only 138 patients and was negative. ${ }^{27}$ Two recent meta-analyses report a significant reduction in blood transfusion using intravenous TXA in patients with HF; however, the heterogeneity is important $\left(\mathrm{I}^{2}=60 \%\right)$ and the sample size is too small to evaluate the tolerance of this treatment. ${ }^{28}{ }^{29}$ In addition, use of intravenous TXA could be limited in this population of frail patients and topical use of TXA appears to be an effective and safe alternative, at least in major orthopaedic surgery patients. ${ }^{30-32}$ It has also been reported that the combined use of intravenous and topical TXA may be superior to intravenous alone in orthopaedic surgery patients. ${ }^{33} 34$

Although HF is a very frequent pathology, with a high burden of care, few data are available that focus on the management of perioperative anaemia in this context. The interest for perioperative blood management ${ }^{835}$ has recently increased, thanks to better recognition of the adverse effects of blood transfusion, better understanding of iron metabolism, new intravenous iron drugs and a renewed interest in former medications (ie, TXA). ${ }^{836} \mathrm{We}$ therefore propose to evaluate the interest of intravenous iron and TXA to reduce blood transfusion in patients with $\mathrm{HF}$, through a $2 \times 2$ factorial design study.

\section{METHODS AND DESIGN}

\section{Hypothesis and study objectives}

We made three hypotheses for this $2 \times 2$ factorial randomised trial in patients undergoing emergency surgery for HF with a preoperative $\mathrm{Hb}$ between 95 and $130 \mathrm{~g} / \mathrm{L}$ :

1. That a preoperative infusion of $20 \mathrm{mg} / \mathrm{kg}$ of IIM will reduce the need for red blood cell transfusion during the hospital stay after surgery (or until D30 if the patient is still hospitalised).

2. That the administration of TXA (intravenously preoperatively and topically during surgery) will reduce the need for red blood cell transfusion during the hospital stay after surgery (or until D30 if the patient is still hospitalised).

3. That there will be no interaction between the two treatments.

\section{Trial design}

This is a multicentre, $2 \times 2$ factorial, randomised, doubleblinded, controlled study of parallel groups. Two arms will be compared: IIM versus its placebo $\left(\mathrm{P}_{\text {IIM }}\right)$ and TXA versus its placebo $\left(\mathrm{P}_{\mathrm{TXA}}\right)$. Patients will be included in four 
groups (see figure 1). This study protocol is composed according to the Standard Protocol Items: Recommendations for Interventional Trials (SPIRIT) statement. The SPIRIT checklist is provided in the supplementary files as well as the full study protocol (see online supplemental file 1).

\section{Study population}

Patients hospitalised for a HF and scheduled for HF surgery will be approached by the study investigators as soon as possible. Eligibility criteria are presented in table 1. Very dependent patients are not eligible (corresponding to a GIR 1 or 2 class). The GIR classification ${ }^{37}$ (from the French 'autonomy gerontology groups isoresources') classifies patients' dependency from 1 (very dependent) to 6 (autonomous).

\section{Setting}

The study involves 13 French public, university and private hospitals.

\section{Treatment allocation}

Randomisation will be performed using a web-based system (Clinsight software). Patients will be randomly assigned in a 1:1:1:1 ratio to one of the four groups (figure 1) using a minimisation algorithm based on four determinants:

- HF type (extracapsular or intracapsular).

- Chronic use of anticoagulant/antiaggregant therapy (excluding salicylic acid).

- Time to hospital admission ( $<48$ hours or $\geq 48$ hours from HF).

- Centre.

\section{Intervention}

Study medications will be infused as soon as possible after randomisation as follows:

- IMM (iron isomaltoside, MONOFER, Pharmacosmos, Denmark) or $\mathrm{P}_{\text {IIM }}$ (placebo IIM) will be infused as a 30 -minute bolus infusion, after dilution of $20 \mathrm{mg} /$ $\mathrm{kg}$ or placebo in $\mathrm{NaCl} 0.9 \%$. An 'open' nurse will dilute $20 \mathrm{~mL}$ of IMM/P $\mathrm{P}_{\text {IIM }}$ in $40 \mathrm{~mL}$ of saline, in $60 \mathrm{~mL}$ syringe. The volume to be administered will be calculated according to the patient's weight (automatically calculated in the eCRF). This volume is calculated using the following formula: Administered volume $(\mathrm{mL})=$ patientweight $(\mathrm{kg}) / 2$. The infusion rate $(\mathrm{mL} / \mathrm{h})$ corresponds to patient's weight (in order to infuse the solution over a 30-minute period).

- One gram of TXA (tranexamic acid, EXACYL, SanofiAventis, France) or an identical volume of $\mathrm{P}_{\mathrm{TXA}}$ will be infused as a slow bolus infusion after dilution in $50 \mathrm{~mL}$ of $\mathrm{NaCl} 0.9 \%$ followed by a continuous infusion using an automated syringe ( $1 \mathrm{~g}$ or placebo in $48 \mathrm{~mL}$ of $\mathrm{NaCl}$ $0.9 \%$ ) over 8 hours (infusion speed: $6 \mathrm{~mL} /$ hour).

- Three grams of TXA or $\mathrm{P}_{\text {TXA }}$ will be administered topically during surgery using two $60 \mathrm{~mL}$ syringes. During surgery, the anaesthetic nurse will dilute $30 \mathrm{~mL}$ of TXA or placebo in a saline bag of $100 \mathrm{~mL}(\mathrm{NaCl} 0.9 \%)$. The surgeon will draw, through the saline bag in sterile conditions, two syringes of $60 \mathrm{~mL}$ of the solution for topical administration.

- The first syringe will be topically administered just before implantation of the orthopaedic device by the surgeon who will wait at least 5 min before continuing the surgery.

- The second syringe will be used at the end of surgery, just before skin closure. The study medication $(60 \mathrm{~mL})$ will be spread over the wound; the suction drains, if present, will not be open during the first 5 min following application.

Nurses at each participating centre will learn to identify hypersensitivity reactions including serious and potentially fatal anaphylactic/anaphylactoid reactions following iron injection, and resuscitation material as well as medical teams are available at any time with no delay in case of emergency at all the study centres.

\section{Blinding}

Because IIM is a dark brown solution easily distinguishable from placebo, 'open' nurses are required for study medication preparation and infusion, they will not be involved in data collection, in study assessments or in patient care. Preparation of study medication (open-label) will be performed in a different room so that the physician or nurses in charge cannot observe it. In addition, a curtain will be used to cover the syringe and a jersey will cover the injection site and the intravenous line from the patient's view. At the end of infusion, the intravenous line will be flushed using $10 \mathrm{~mL}$ of saline before removing the curtain so that no dark solution remains in the intravenous line.

TXA and $\mathrm{P}_{\mathrm{TXA}}$ look the same, so that no blinding material is needed. During surgery, an anaesthetic nurse, not involved in patient's care, will prepare the solution, so that the surgeon and the anaesthetist cannot see the treatment vials. Thus, all physicians and personnel involved in patient's care will remain blind to the treatment received and the patient too.

\section{Procedures}

Patients hospitalised for a HF and scheduled for hip surgery will be approached by the study investigators as soon as possible. After having verified the presence of all inclusion criteria and the absence of exclusion criteria, complete oral and written information about the study will be given to each patient (the patient's consent form is presented in online supplemental file 2). Inclusion will be effective as soon as the patient has signed the consent form after a sufficient reflection period. In case of inability for the patient to consent, the study investigator will inform the patient's next of kin in order to obtain his/her consent, as soon as able, the patient will have to be informed and to sign a consent himself to continue his study participation. If patient cannot consent and patient's relatives cannot be contacted in time, the study investigators may enrol the patient through an emergency procedure. In the latter two cases, investigators inform 


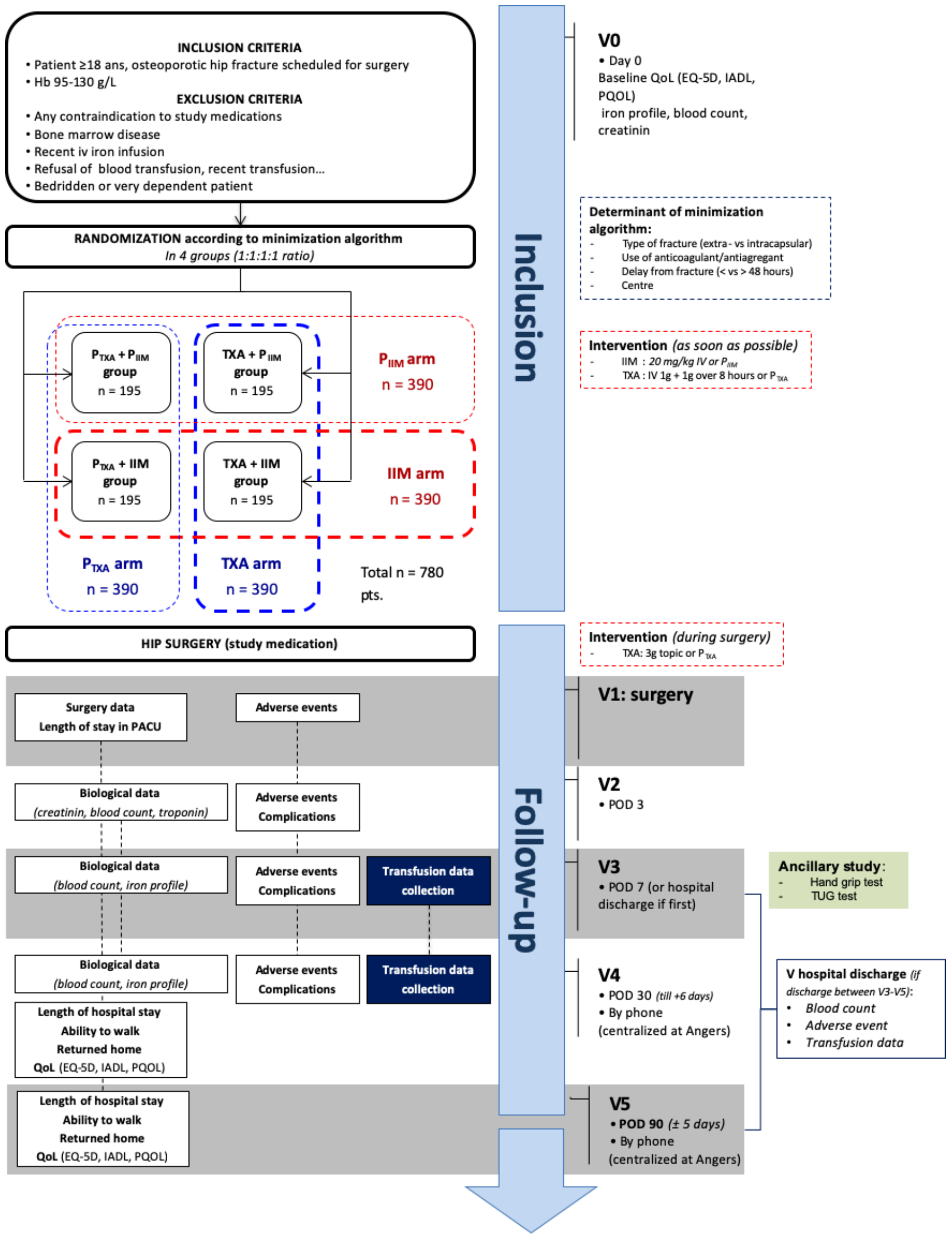

Figure 1 HiFIT study overview. Iron profile includes blood tests for ferritin, transferrin saturation and C reactive protein. EQ-5D, EuroQol 5 Dimensions; IADL, Instrumental Activities of Daily Living; IIM, iron isomaltoside; PQoL, perceived QoL; $P_{\text {IIM, }}$, placebo for IIM (=saline); $\mathrm{P}_{\text {TXA }}$, placebo of TXA (=saline); POD, postoperative day; pts, patients; QoL, quality of life; TUG, timed up and go test; TXA, tranexamic acid; $V$, visit. 
Table 1 Patient's eligibility criteria for the HiFIT study

Inclusion criteria

Patient $\geq 18$ years old, hospitalised for an osteoporotic HF (eg, femoral neck fracture, subtrochanteric or intertrochanteric fracture) scheduled for a HF surgery.

Preoperative haemoglobin between 95 and $130 \mathrm{~g} / \mathrm{L}(95 \leq \mathrm{Hb} \leq 130 \mathrm{~g} / \mathrm{L})$.

Signed informed consent of the patient or his/her next of kin or emergency procedure for inclusion.

Exclusion criteria Bone marrow disease or ongoing treatment (such as chemotherapy, etc), which could interfere with bone marrow erythropoiesis.

Known allergy or contraindication to study drug.

Uncontrolled hypertension.

Recent intravenous infusion of iron (within 1 week). (Use of oral iron is not an exclusion criteria.)

Blood transfusion within 1 week before inclusion or preoperative blood transfusion already scheduled, any patient who cannot be transfused or has refused consent for a blood transfusion.

Bedridden or very dependent patient (equivalent to GIR 1 or 2 class).

Non-affiliation to French healthcare coverage. Adult patient protected under the law (guardianship).

Pregnancy.

The GIR classification ${ }^{37}$ (from the French 'autonomy gerontology groups iso-resources') is used to classify patients' dependency from 1 (very dependent) to 6 (autonomous).

$\mathrm{Hb}$, haemoglobin; HF, hip fracture.

patient and research the patient's consent (as soon as the health status allows).

The choice of anaesthesia type (general and/or loco regional) will be left to the discretion of the attending physician. Management of perioperative anticoagulation therapy, antiplatelet agent, antibioprophylaxis and thromboprophylaxis will follow the recommendations of the French Society of Anaesthesiology (SFAR, Société Française d'Anesthésie Réanimation) ${ }^{38}$ The use of low molecular weight heparin preoperatively for thromboprophylaxis is recommended (eg, enoxaparin $40 \mathrm{mg}$, in the absence of renal insufficiency).

Attending physicians and research personnel will remain blind to the treatment administered.

Seven visits are scheduled for all patients enrolled in the study (see figure 1). All data, anonymised, will be collected in an electronic clinical research form (eCRF). A detailed description of the procedures is available in online supplemental files 1 .

\section{Outcome measures}

Primary endpoint

The primary endpoint will be the proportion of patients receiving an allogenic blood transfusion of packed red blood cells from the day of surgery until hospital discharge (or until D30 if the patient remains hospitalised).

Recommendations for red blood cells transfusion will be made in each centre based on the FOCUS study ${ }^{39}$ and the 'Haute Autorité de Santé' (HAS) recommendations on transfusion. ${ }^{40}$ The recommended transfusion trigger will be a $\mathrm{Hb}$ level below $80 \mathrm{~g} / \mathrm{L}$ or symptoms of anaemia (chest pain thought to be cardiac in origin; congestive heart failure; unexplained tachycardia or hypotension; signs of volume depletion unresponsive to fluid replacement).
The occurrence of any transfusion of packed red blood cells, fresh frozen plasma or platelets as well as the number of units and the date of transfusion will be recorded in the transfusion file of the patient. The recording of transfusions on a patient's chart is a legal obligation. Therefore, no missing data are anticipated.

\section{Secondary endpoints and ancillary study}

- The proportion of transfused patients and the number of transfused units per patient (including red blood cells, fresh frozen plasma and platelets) on postoperative day (POD) 3, POD7, hospital discharge and POD30.

- Postoperative Hb levels and anaemia rate (WHO definition: $\mathrm{Hb}<130 \mathrm{~g} / \mathrm{L}$ for men and $<120 \mathrm{~g} / \mathrm{L}$ for women) on POD3, POD7, hospital discharge and POD30.

- Perioperative blood loss will be estimated according to the following published formula ${ }^{41}$ : $(\mathrm{HtD} 0-\mathrm{HtD} 3) * \mathrm{~TB}-$ $\mathrm{V}+$ number of RPBC transfused unit $\times 200 \mathrm{~mL}$. Ht=haematocrit, $\mathrm{TBV}=$ total blood volume $(70 \mathrm{~mL} / \mathrm{kg}$ in men and $65 \mathrm{~mL} / \mathrm{kg}$ in women).

- Postoperative iron deficiency (defined as a ferritin $<100 \mu \mathrm{g} / \mathrm{L}$ or $<300 \mu \mathrm{g} / \mathrm{L}$ together with transferrin saturation $<20 \%$, according to the FAIR-HF study definition ${ }^{42}$ ); on D0, POD7 (or hospital discharge if it happens first) and POD30.

- Postoperative rehabilitation on POD30 and POD90, as follows:

- Number of hospitalisation days after surgery.

- Proportion of patients returned at home (or at their previous place of living).

- Proportion of patients able to walk a distance of 10 feet without assistance (the same criteria used in the FOCUS study). ${ }^{39}$ 
- Quality of life (QoL) using the variation of EQ-5D score $^{43}$ from admission to POD30 and POD90 and on perceived QoL with a single overall item from PQoL scale $^{44}$ from admission to POD7 and POD90.

- Dependencies of patients for daily life activities using the variation of IADL test (Instrumental Activities of Daily Living $)^{45}$ from inclusion to POD90.

- Safety will be evaluated according to:

- Death rate from all causes until POD90.

- Rate of adverse events (AEs) until POD90 including the following clinical complications: vascular events (all kinds of cerebrovascular accidents, acute coronary syndrome (defined by an increase in troponin with or without EKG modifications), new venous thrombosis, arterial embolism), heart failure, renal failure (assessed by a creatinine level according to RIFLE criteria), ${ }^{46}$ infectious complications (pneumonia, urinary tract infection, surgical site infection, bloodstream infection and so on), any anaphylactic reaction and severe anaemia defined as a $\mathrm{Hb}<80 \mathrm{~g} / \mathrm{L}$. Troponin and creatinine concentrations will be measured on POD3.

An ancillary study will be performed in selected centres to assess if IIM and/or the correction of iron deficiency will improve postoperative functional rehabilitation of patients on POD 7 or hospital discharge whichever happens first, by measuring:

- Maximum strength of the hand and forearm muscles assessed by the Hand Grip Strength test.

- Muscular fatigability assessed as the variation of strength measured at the first and the third attempt of the Hand Grip Strength test.

- Level of locomotion and balance assessed by the Timed 'Up and Go' test. ${ }^{47}$

\section{Monitoring}

A clinical research associate mandated by the study sponsor will ensure the successful completion of the study, the collection of data, documentation, recording and report, in accordance with the Standard Operating Procedures implemented in the Angers Hospital and in accordance with Good Clinical Practice and the laws and regulations.

The following items will be reviewed:

- Signed informed consent.

- Compliance with the study protocol and procedures that are defined.

- Quality of data collected in the case report form: accuracy, missing data, data consistency with the documents 'source' (medical records, appointment books, original lab results and so on).

- Study drug boxes stored at the pharmacy.

After monitoring data on site, an automated check of the data entered will be made by the data management team based on the data validation plan signed by the coordinating investigator. Detected errors will lead to the issuance of requests for information and electronic correction.

\section{Study oversight}

Study sponsor is the Centre Hospitalier Universitaire d'Angers. Experienced research staff monitor the study for quality and the integrity of data in all the participating centres. Serious AEs and unexpected related or possibly related serious events are to be reported to the sponsor within 7 days.

An independent data and safety monitoring board (DSMB) is appointed by the sponsor at the beginning of the study. The DSMB reviews safety issues as the study progresses, with a meeting every 200 patients included. The DSMB makes recommendations to the sponsor about the continuation, modification or termination of the research.

In addition, an independent adjudication committee of three experts (in anaphylaxis, thrombosis and infectious disease) has been named at the beginning of the study. It will be assembled to review any expected as well as unexpected AEs related to study medication (mainly anaphylaxis and infection for iron; thrombosis and renal failure for TXA). Their report will be available for the DSMB before each meeting. Specific report forms for anaphylaxis, septic and thrombosis AEs are available in the eCRF.

\section{Sample size calculation}

We have reviewed the charts of 402 patients operated in 2013 at the CHU Angers. Among them, the transfusion rate was $41 \%$. Considering only the 261 (65\%) patients meeting our inclusion criteria, this transfusion rate was $50 \%$. Based on these data and the literature, ${ }^{561539}$ we expect a transfusion rate of $50 \%$ in each placebo arm $\left(\mathrm{P}_{\text {IIM }}\right.$ and $\mathrm{P}_{\text {TXA }}$ arms $)$. We expect an absolute reduction of transfusion rate of $10 \%$ for the IIM arm and of $15 \%$ for the TXA arm, which were the lowest magnitude of the effects observed for the two drugs in previous studies. ${ }^{126}$ We hypothesise an absence of interaction between the two drugs. According to these hypotheses, with an alpha risk of 0.05 and a power of 0.8 , a bilateral test, the total number of patients needed is 390 per arm (195 per group), representing a total of 780 patients. Because our primary endpoint is short term and easy to obtain (blood transfusion traceability in patient files is required by law), we do not expect any missing data for the primary endpoint. In addition, in case of interaction between the two treatment arms, the study will still have a 0.82 power to detect a difference in transfusion rate from $50 \%$ to $35 \%$ for TXA versus $\mathrm{P}_{\mathrm{TXA}}$.

\section{Statistical analysis}

A flow chart of the patients (included or not) and descriptive statistics will be used to describe baseline characteristics as well as the outcome measures of patients in each arm.

All comparisons will be performed first in intention-totreat analysis (all patients fulfilling the inclusion criteria/ exclusion criteria and randomised) and then per-protocol analysis (all patients treated according to their treatment allocation, excluding protocol violations). 
Comparability of each arm will be checked, with regard to factors known to influence the transfusion rate (mainly preoperative $\mathrm{Hb}$, history of coronary artery disease, body weight, gender, use of anticoagulation therapy, delay of surgery, type of HF, type of surgery, surgeon experience, preoperative iron deficiency). A site effect will also be checked.

\section{Primary endpoint analysis}

The absence of statistically significant interaction between the two study drugs on the transfusion rate will be tested before any further analysis using a fixed-effect logistic regression model. The proportion of transfused patients during their hospital stay will then be compared respectively in IIM versus $\mathrm{P}_{\text {IIM }}$ and in TXA versus $\mathrm{P}_{\text {TXA }}$ patients, using a $\chi^{2}$ test (Fisher's exact test). In case of imbalance between groups (IIM vs $\mathrm{P}_{\text {IIM }}$ and TXA vs $\mathrm{P}_{\text {TXA }}$ ), an adjusted analysis will be performed.

\section{Secondary endpoints}

The absence of statistically significant interaction between the two study drugs will then be tested for secondary endpoints before each comparison. The following parameters will be compared between TXA versus $\mathrm{P}_{\mathrm{TXA}}$ and IIM versus $\mathrm{P}_{\text {IIM }}$ groups, respectively, using a $\chi^{2}$ or a MannWhitney test, as appropriate.

* Prespecified subgroup analysis will be performed for the same comparisons with regard to

- Presence or not of anticoagulation/antiaggregant therapy.

- Type of HF (extracapsular or intracapsular) and type of HF surgery.

- Presence or not of iron deficiency at baseline (defined as a ferritin $<100 \mu \mathrm{g} / \mathrm{L}$ or $<300 \mu \mathrm{g} / \mathrm{L}$ together with transferrin saturation $<20 \%$ ).

- Delay between trauma and surgery $(<48$ hours or $\geq 48$ hours).

One interim analysis will be scheduled after recruitment of 390 patients; if a significant effect is found at $\mathrm{p}<0.001$, for IIM versus $\mathrm{P}_{\text {IIM }}$ or TXA versus $\mathrm{P}_{\text {TXA }}$ comparisons, the study (or one of its arm) will be stopped. In the absence of significant differences, the study will continue, with statistical significance set at $\mathrm{p}<0.05$ (Haybittle-Peto method to keep the alpha risk at 5\%).

\section{Patient and public involvement}

No patient involved.

\section{ETHICS AND DISSEMINATION}

The HiFIT trial protocol has been approved by the Ethics Committee of The Comité de Protection des Personnes Ouest II (number 2016/42, approval date 15 November 2016), by the Agence Nationale de Sécurité du Médicament (ANSM, Number 160828A-21, approval date 27 December 2016), by the 'Commission Nationale Informatique et Liberté' (CNIL, decision DR-2017-390, approval date 14 December 2017) and by the 'Comité
Consultatif sur le Traitement de l'Information en matière de Recherche sans le domaine de la Santé' (CCTIRS, Number 16-716, approval date 29 September 2016). The actual version of the protocol is No. 10 .

The results of this study will be disseminated through presentation at scientific conferences and publication in peer-reviewed journals.

\section{Data sharing}

The coordinating investigator will have access to the final study dataset. Data sharing: patient level data and/or full dataset and/or statistical code will be available on request to the corresponding author. Consent was not obtained but the data presented are anonymised and the risk of identification is low and the potential benefits of sharing these data outweigh the potential harm.

\section{Trial status}

The trial has already achieved many milestones. After approval by the ethics committee and the authorities, the trial has been registered on clinicaltrial.gov (NCT02972294) on 23 November 2016 and inclusions started on 31 March 2017. The trial has been suspended between 24 July 2017 and 18 July 2018 because of new information about safety regarding the IIM, reported by Spanish System of Pharmacovigilance on 5 July 2017 to the European Medicines Agency. Among 108 reported cases of serious anaphylactic reactions or serious clinical situations related to anaphylaxis/anaphylactic shock, associated with the intravenous administration of any of the iron preparations, 44 were related to administration of IIM. Because this signal was not confirmed elsewhere in Europe, the agencies' recommendations regarding intravenous iron treatments, including IIM, were not modified (neither by the European nor the by the French Medicine Agencies) and the study was authorised to restart. Since mid-March 2020, due to the pandemic of COVID-19 pneumonia, the study recruitment has slowed down dramatically after the inclusion of 245 patients. Two centres remain open for inclusions. End of recruitment is expected in early 2022, with the last follow-up in May 2022 (depending on the evolution of the COVID-19 crisis).

\section{DISCUSSION}

Anaemia and blood transfusion are both frequent and are associated with poorer outcome in surgical patients, justifying the concept of patient blood management. ${ }^{835}$ However, management of perioperative anaemia requires time, ${ }^{9}$ which is not available in case of emergency surgery, such as HF surgery. Furthermore, in elderly patients, anaemia (and iron deficiency) is even more frequent. ${ }^{6}$ The benefit of giving iron preoperatively to reduce blood transfusion is not proven yet in large randomised controlled study, ${ }^{48}$ but may be of great interest in this population of frail patients. ${ }^{11-13}$

TXA has proven its efficacy in many surgeries, including orthopaedic surgery, ${ }^{24}$ but data are still scarce in 
patients with HF, without any definitive data regarding safety. ${ }^{26}{ }^{29}$ In addition, the association of intravenous and topical TXA may be superior, without increase in side effects. ${ }^{34}$ The HiFIT trial will be the largest study in patients with HF to evaluate (1) the interest of a preoperative high-dose intravenous iron and (2) the interest of TXA (administered intravenously and topically) on rate of blood transfusion.

The HiFIT study, in its ancillary part, will also investigate the impact of iron deficiency on postoperative strength and recovery, as well as the benefit of treating it. Indeed, iron deficiency is frequent in the elderly, is associated with fatigue and its treatment may be beneficial. ${ }^{20-22} 42$ It will also evaluate the impact of these treatments on patients' quality of life after surgery.

The trial encountered difficulties because of numerous external events: 'new events' with IIM requiring 1 year of study suspension and recently the COVID-19 crisis. However, this study should provide definitive information on the interest of two main pillars of patient blood management programmes: high-dose intravenous iron and TXA, in a specific patients' population: the patients with $\mathrm{HF}$.

\section{Author affiliations}

${ }^{1}$ Département Anesthésie Réanimation, Centre Hospitalier Universitaire d'Angers, Angers, France

${ }^{2}$ Service d'anesthésie réanimation A, Université de Montpellier, CHU de Montpellier, Montpellier, France

${ }^{3}$ Département de Biostatistiques et Méthodologie, Centre Hospitalier Universitaire d'Angers, Angers, Pays de la Loire, France

${ }^{4}$ Anaesthesia and Intensive Care Unit, Clermont-Tonnerre Military Hospital, Brest, France

${ }^{5}$ Service d'Anesthésie Réanimation, CHU Nantes, Nantes, France

${ }^{6}$ Département d'Anesthésie Réanimation, CHU Rennes, Rennes, France

${ }^{7}$ Département Anesthésie Réanimation, Medipole Lyon-Villeurbanne, Villeurbanne, France

${ }^{8}$ Ramsay Santé, Clinique de la Sauvegarde, Lyon, France

${ }^{9}$ Service d'anesthésie reanimation, CHD Vendée, La Roche-sur-Yon, France

${ }^{10}$ Emergency Department and Prehospital Care, Centre Hospitalier Universitaire de

Poitiers, Poitiers, France

${ }^{11}$ Universite de Poitiers UFR Medecine et Pharmacie, Poitiers, France

${ }^{12}$ Département d'Anesthésie Réanimation, Centre Hospitalier Universitaire de Grenoble, Grenoble, France

${ }^{13}$ Pôle d'Anesthésie Réanimation, Pôle de l'Urgence, CHRU, Lille, Hauts-de-France, France

${ }^{14}$ Service d'Anesthésie Réanimation, Clinique de l'Anjou, Angers, France

${ }^{15}$ Service d'anesthésie réanimation, CHU Lyon Sud, Lyon, France

\section{Twitter Marc Danguy des Déserts @MarcDDD and Maxime Leger @mxmleger}

Acknowledgements We thank patients and relatives, physicians, nursing staff and clinical research associates of the participating centres for their involvement in this study.

Collaborators HiFIT study group: CHU Angers: Guillaume BOUHOURS, Sigismond LASOCKI, Adeline LEBAIL, Maxime LEGER, Emmanuel RINEAU, Elsa PAROT-SCHINKEL, Emmanuel SAMSON, Bruno VIELLE, CHU de Montpellier: Xavier CAPDEVILLA, Thibault LOUPEC, Benjamin MOUNET, Fabien SWISSER, HIA Clermont-Tonnerre: Marc DANGUY DES DESERTS, CHU Nantes: Karim ASEHNOUNE, Antoine ROQUILLY, CHU de Rennes: Hélène BELOEIL, Maria LAHLOU-CASULLI, Medipôle, Lyon Villeurbanne: Vincent COLLANGE, Sébastien PARENT, Clinique de la Sauvegarde, Lyon: Olivier DESEBBE, CHD Vendée: Alexis DUCHALAIS, CHU Poitiers: Bertrand DRUGEON, Olivier MIMOZ, CHU Grenoble: Pierre BOUZAT, Gaetan GAVAZZI, CHRU Lille: Benjamin BIJOK, Delphine GARRIGUE, Clinique de l'Anjou: Franck HAMARD, CHU Lyon-Sud: Jean-Stéphane DAVID.
Contributors SL conceived the study. SL, EP-S and ER coordinated its design. SL drafted the manuscript. SL, TL, EP-S, BV, MDD, AR, MLC, VC, OD, AD, PB, BD, DG, $\mathrm{BM}, \mathrm{FH}, \mathrm{JSD}, \mathrm{ML}$ and ER read and were involved in critical appraisal and revision of the manuscript. BV provided statistical expertise. All authors approved the final manuscript prior to submission.

Funding This study is an investigator-initiated trial, funded by a grant from the French Ministry of Health (PHRC-N 2015, 15-371). Iron isomaltoside is given for free by PHARMACOSMOS, without any implication in the study design, conduct or in analysis of the result.

Competing interests SL: Lecturer personally funded by Pfizer, Vifor Pharma, Masimo; consulting for Pfizer, Vifor Pharma; research support from Vifor Pharma.

Patient consent for publication Not required.

Ethics approval Comité de Protection des Personnes Ouest II (number 2016/42, approval date 11/15/2016). Agence Nationale de sécurité du Médicament (ANSM, Number 160828A-21, approval date 12/27/2016), by the "Commission Nationale Informatique et Liberté" (CNIL, decision DR-2017-390, approval date 12/14/2017) and by the "Comite Consultatif sur le Traitement de l'Information en matière de Recherche sans le domaine de la Santé" (CCTIRS, Number 16-716, approval date 09/29/2016).

Provenance and peer review Not commissioned; externally peer reviewed.

Supplemental material This content has been supplied by the author(s). It has not been vetted by BMJ Publishing Group Limited (BMJ) and may not have been peer-reviewed. Any opinions or recommendations discussed are solely those of the author(s) and are not endorsed by BMJ. BMJ disclaims all liability and responsibility arising from any reliance placed on the content. Where the content includes any translated material, BMJ does not warrant the accuracy and reliability of the translations (including but not limited to local regulations, clinical guidelines, terminology, drug names and drug dosages), and is not responsible for any error and/or omissions arising from translation and adaptation or otherwise.

Open access This is an open access article distributed in accordance with the Creative Commons Attribution Non Commercial (CC BY-NC 4.0) license, which permits others to distribute, remix, adapt, build upon this work non-commercially, and license their derivative works on different terms, provided the original work is properly cited, appropriate credit is given, any changes made indicated, and the use is non-commercial. See: http://creativecommons.org/licenses/by-nc/4.0/.

\section{ORCID iDs}

Sigismond Lasocki http://orcid.org/0000-0003-2901-4628

Pierre Bouzat http://orcid.org/0000-0003-4667-6738

\section{REFERENCES}

1 Veronese N, Maggi S. Epidemiology and social costs of hip fracture. Injury 2018:49:1458-60.

2 Cummings SR, Rubin SM, Black D. The future of hip fractures in the United States. numbers, costs, and potential effects of postmenopausal estrogen. Clin Orthop Relat Res 1990;252:163-6.

3 Aubrun F. [Hip fracture surgery in the elderly patient: epidemiological data and risk factors]. Ann Fr Anesth Reanim 2011;30:e37-9.

4 Le Manach Y, Collins G, Bhandari M, et al. Outcomes after hip fracture surgery compared with elective total hip replacement. JAMA 2015;314:1159-66.

5 Potter LJ, Doleman B, Moppett IK. A systematic review of preoperative anaemia and blood transfusion in patients with fractured hips. Anaesthesia 2015;70:483-500.

6 Spahn DR. Anemia and patient blood management in hip and knee surgery: a systematic review of the literature. Anesthesiology 2010;113:482-95.

7 Williamson LM, Devine DV. Challenges in the management of the blood supply. Lancet 2013;381:1866-75.

8 Mueller MM, Van Remoortel H, Meybohm P, et al. Patient blood management: recommendations from the 2018 Frankfurt consensus conference. JAMA 2019;321:983-97.

9 Muñoz M, Acheson AG, Auerbach M, et al. International consensus statement on the peri-operative management of anaemia and iron deficiency. Anaesthesia 2017;72:233-47.

10 Gupta PB, DeMario VM, Amin RM, et al. Patient blood management program improves blood use and clinical outcomes in orthopedic surgery. Anesthesiology 2018;129:1082-91.

11 Gómez-Ramírez S, Maldonado-Ruiz María Ángeles, CamposGarrigues A, et al. Short-Term perioperative iron in major orthopedic surgery: state of the art. Vox Sang 2019;114:3-16. 
12 Muñoz M, Gómez-Ramírez S, Cuenca J, et al. Very-Short-Term perioperative intravenous iron administration and postoperative outcome in major orthopedic surgery: a pooled analysis of observational data from 2547 patients. Transfusion 2014;54:289-99.

13 Serrano-Trenas JA, Ugalde PF, Cabello LM, et al. Role of perioperative intravenous iron therapy in elderly hip fracture patients: a single-center randomized controlled trial. Transfusion 2011;51:97-104.

14 Moppett IK, Rowlands M, Mannings AM, et al. The effect of intravenous iron on erythropoiesis in older people with hip fracture. Age Ageing 2019;48:751-5.

15 Bernabeu-Wittel M, Romero M, Ollero-Baturone M, et al. Ferric carboxymaltose with or without erythropoietin in anemic patients with hip fracture: a randomized clinical trial. Transfusion 2016:56:2199-211.

16 Johansson PI, Rasmussen AS, Thomsen LL. Intravenous iron isomaltoside 1000 (Monofer $\AA$ ) reduces postoperative anaemia in preoperatively non-anaemic patients undergoing elective or subacute coronary artery bypass graft, valve replacement or a combination thereof: a randomized double-blind placebo-controlled clinical trial (the protect trial). Vox Sang 2015;109:257-66.

17 Bielza R, Llorente J, Thuissard IJ, et al. Effect of intravenous iron on functional outcomes in hip fracture: a randomised controlled trial. Age Ageing 2020. doi:10.1093/ageing/afaa107. [Epub ahead of print: 15 Jun 2020].

18 Schultz BM, Freedman ML. Iron deficiency in the elderly. Baillieres Clin Haematol 1987;1:291-313.

19 Brutsaert TD, Hernandez-Cordero S, Rivera J, et al. Iron supplementation improves progressive fatigue resistance during dynamic knee extensor exercise in iron-depleted, nonanemic women. Am J Clin Nutr 2003;77:441-8.

20 Verdon F, Burnand B, Stubi C-LF, et al. Iron supplementation for unexplained fatigue in non-anaemic women: double blind randomised placebo controlled trial. BMJ 2003;326:1124.

21 Krayenbuehl P-A, Battegay E, Breymann C, et al. Intravenous iron for the treatment of fatigue in nonanemic, premenopausal women with low serum ferritin concentration. Blood 2011;118:3222-7.

22 Piednoir P, Allou N, Driss F, et al. Preoperative iron deficiency increases transfusion requirements and fatigue in cardiac surgery patients: a prospective observational study. Eur J Anaesthesiol 2011;28:796-801.

23 CRASH-2 trial collaborators, Shakur H, Roberts I, et al. Effects of tranexamic acid on death, vascular occlusive events, and blood transfusion in trauma patients with significant haemorrhage (CRASH-2): a randomised, placebo-controlled trial. Lancet 2010;376:23-32.

24 Houston BL, Uminski K, Mutter T, et al. Efficacy and safety of tranexamic acid in major non-cardiac surgeries at high risk for transfusion: a systematic review and meta-analysis. Transfus Med Rev 2020;34:51-62.

25 Pavenski K, Ward SE, Hare GMT, et al. A rationale for universal tranexamic acid in major joint arthroplasty: overall efficacy and impact of risk factors for transfusion. Transfusion 2019;59:207-16.

26 Zufferey PJ, Miquet M, Quenet S, et al. Tranexamic acid in hip fracture surgery: a randomized controlled trial. $\mathrm{Br} J$ Anaesth 2010;104:23-30.

27 Watts CD, Houdek MT, Sems SA, et al. Tranexamic acid safely reduced blood loss in Hemi- and total hip arthroplasty for acute femoral neck fracture: a randomized clinical trial. J Orthop Trauma 2017;31:345-51.

28 Haj-Younes B, Sivakumar BS, Wang M, et al. Tranexamic acid in hip fracture surgery: a systematic review and meta-analysis. J Orthop Surg 2020;28:230949901988799.
29 Qi Y-M, Wang H-P, Li Y-J, et al. The efficacy and safety of intravenous tranexamic acid in hip fracture surgery: a systematic review and meta-analysis. J Orthop Translat 2019;19:1-11.

30 Montroy J, Hutton B, Moodley P. The efficacy and safety of topical tranexamic acid: a systematic review and meta-analysis. Transfus Med Rev 2018:30151-7. doi:10.1016/j.tmrv.2018.02.003

31 Chen Y, Chen Z, Cui S, et al. Topical versus systemic tranexamic acid after total knee and hip arthroplasty: a meta-analysis of randomized controlled trials. Medicine 2016;95:e4656.

32 Teoh WY, Tan TG, Ng KT, et al. Prophylactic topical tranexamic acid versus placebo in surgical patients: a systematic review and metaanalysis. Ann Surg 2020. doi:10.1097/SLA.0000000000003896. [Epub ahead of print: 08 Apr 2020].

33 Sun Y, Jiang C, Li Q. A systematic review and meta-analysis comparing combined intravenous and topical tranexamic acid with intravenous administration alone in THA. PLoS One 2017;12:e0186174.

34 Zhang $\mathrm{H}$, He G, Zhang $\mathrm{C}$, et al. Is combined topical and intravenous tranexamic acid superior to intravenous tranexamic acid alone for controlling blood loss after total hip arthroplasty?: a meta-analysis. Medicine 2017:96:e6916.

35 Shander A, Van Aken H, Colomina MJ, et al. Patient blood management in Europe. Br J Anaesth 2012;109:55-68.

36 Spahn DR, Goodnough LT. Alternatives to blood transfusion. Lancet 2013;381:1855-65

37 Vetel JM, Leroux R, Ducoudray JM. [AGGIR. Practical use. Geriatric Autonomy Group Resources Needs]. Soins Gerontol 1998:23-7.

38 Mantz J, Samama CM, Tubach F, et al. Impact of preoperative maintenance or interruption of aspirin on thrombotic and bleeding events after elective non-cardiac surgery: the multicentre, randomized, blinded, placebo-controlled, stratagem trial. $\mathrm{Br} J$ Anaesth 2011;107:899-910.

39 Carson JL, Terrin ML, Noveck H, et al. Liberal or restrictive transfusion in high-risk patients after hip surgery. $N$ Engl J Med 2011;365:2453-62.

40 HAS, ANSM. Recommandation de bonne pratique: Transfusion de globules rouges homologues: produits, indications, alternatives, 2014. Available: https://wwwhas-santefr/portail/upload/docs/ application/pdf/2015-02/transfusion_de_globules_rouges homologues_-_anesthesie_reanimation_chirurgie_urgence_-_ argumentairepdf

41 Rosencher N, Kerkkamp HEM, Macheras G, et al. Orthopedic surgery transfusion hemoglobin European overview (OSTHEO) study: blood management in elective knee and hip arthroplasty in Europe. Transfusion 2003;43:459-69.

42 Anker SD, Comin Colet J, Filippatos G, et al. Ferric carboxymaltose in patients with heart failure and iron deficiency. $N$ Engl J Med 2009;361:2436-48.

43 EuroQol Group. EuroQol--a new facility for the measurement of health-related quality of life. Health Policy 1990;16:199-208.

44 Patrick DL, Danis M, Southerland LI, et al. Quality of life following intensive care. J Gen Intern Med 1988;3:218-23.

45 Pérès K, Chrysostome V, Fabrigoule C, et al. Restriction in complex activities of daily living in $\mathrm{MCl}$ : impact on outcome. Neurology 2006;67:461-6.

46 Venkataraman R, Kellum JA. Defining acute renal failure: the rifle criteria. J Intensive Care Med 2007;22:187-93.

47 Podsiadlo D, Richardson S. The timed "Up \& Go": a test of basic functional mobility for frail elderly persons. J Am Geriatr Soc 1991;39:142-8.

48 Richards T, Baikady RR, Clevenger B, et al. Preoperative intravenous iron to treat anaemia before major abdominal surgery (PREVENTT): a randomised, double-blind, controlled trial. Lancet 2020;396:1353-61. 